\title{
\#politicallyincorrect: The Pejoration of Political Language
}

\author{
Ashley Balcazar ${ }^{1 *}$
}

\begin{abstract}
How is the term "political correctness" understood in the context of modern American politics, particularly in the context of the 2016 election? More specifically, what triggers perceived offensiveness in political language? At the crux of the matter is the distinction between oneself or one's social group, those perceived as "the other," and what one is and is not allowed to say in a social forum. This study aims to analyze common language usage and identify factors contributing to the offensification of political language in social media and the types of language in social media that trigger a sense of political outrage. We examine Facebook and Twitter memes, using API searches referring directly to the terms "PC" or "politically correct." Dedoose, a text content-analysis package is used to identify recurring themes in online interactions that are used to criticize perceived political enemies. Results show that themes primarily related to "feminism" and "redneck" reflect cross-cutting cleavages in the political landscape primarily related to Hillary Clinton's candidacy. We also identify significant cleavages in racial identity and quantify these statistically. Our results compliment other recent studies which aim to gauge the impact of social media on political and social polarization.
\end{abstract}

\section{Keywords}

Political Correctness - PC Speech - Memes - Social Media - Content Analysis

${ }^{1}$ Department of Linguistics, University of North Texas

*Faculty Mentor: Dr. Tom Miles

\section{Contents}

\section{Introduction}

1 Background: An Overview of the Controversy

1.1 The Case Against Political Correctness

1.2 The Case for Political Correctness .

1.3 The Efficacy of Gender-Fair Language .....

2 Theories on the Pejoration of Words

2.1 Political Correctness and the Internet

3 Study Design

4 Results

4.1 Liberal Memes.

4.2 Feminist Memes

5 Directions for Future Research

Author Biography

References

\section{Introduction}

The concept of political correctness is widely held to be a product of the 1990s, although the term "politically incorrect" first appeared in the United States in the 1970s. Spanning the political, legislative, and corporate arenas and permeating popular culture, "politically correct," or "PC," quickly

1

2 .2

became a divisive inclusion in the American English lexicon. Language is subject to the collective approval of a society, versity of Michigan-Ann Arbor's recently implemented Designated Pronouns policy, which enables students to select the pronoun by which they choose to be called, drew outrage and ridicule from some. When offered a choice between "he," "she," "they," "ze," or a write-in, student Grant Stroble styled himself, "His Majesty," citing a desire to illustrate the absurdity of the policy.[1] The Cleveland Indians Baseball 
team is beloved by fans but has aroused objections among Native Americans and professional organizations concerned with ethnic stereotyping. Demonstrations have been held on opening day of the team's baseball season every year for the past twenty years in protest of the mascot, Chief Wahoo, and the use of the misnomer, "Indians."

In this study, I aim to identify factors contributing to the offensification of political language. To what extent does the distinction of "the other" influence politically incorrect speech and behaviors?

\section{Background: An Overview of the Controversy}

Galef examines the circumstances contributing to the retirement of words from modern usage. He presents three prevailing movements that perpetuate the loss of vocabulary words: social and technological progress, slang, and political correctness. The exploration of political correctness is rather limited; it is referenced in the introduction but nowhere else. The remainder of the article reads as a nostalgic nod to terms from the days of yore, the author lamenting the loss of words such as "nonplussed," "bumptious," and "chagrined."[2]

Euphemisms are a hallmark of modern politically correct

linguistic constructions. Orwell analyzes the evolution of the English language, citing a "decadence" in modern English that is clumsy and abstract. He asserts that political language is inherently vague and constructed of euphemisms. Political jargon, serves as the "defense of the indefensible," and he cites military operations as examples; for instance, a "pacified" town sounds more palatable than a decimated town.[3] Orwell's commentary on an early form of politically correct language doesn't address political correctness as it is understood in its current context, but it perhaps sheds light on the nature of the phenomenon. He was likely sensitive to the effects of combat and accustomed to hearing war stories recounted in obfuscating language when he wrote this essay

following the end of World War II, and the vague, abstract techniques that Orwell bemoaned in 1946 are similar to the techniques employed today to make a term politically correct.

Hughes offers early examples of language censorship in relation to textbooks and literature, likening the effects of political correctness to those of book burnings. Pressure groups from both ends of the political spectrum frequently influence published content, and Hughes reveals that publishers established "bias and sensitivity panels" as early as 1981 and exercised sweeping exclusions of books published prior to 1970 on the grounds of gender or racial bias.[4]

Communism is often credited with creating the environment in which political correctness could take root. Lessing summarizes, "When the certitudes of communism began to dissolve then collapsed with them-but slowly in some countries-the dogmas of Social Realism; but at once stepped into the vacuum Political Correctness...The submission to the new creed could not have happened so fast and so thoroughly if communist rigidities had not permeated the educated classes everywhere..."

According to Feldstein, it was a product of the divisions between adherents to socialism and communism, originally having been used by the Left against itself; he asserts that it was a reference to the "correct" position of approval regarding Stalin's alliance with Hitler, which drew outrage from opponents.[5] Feldstein cites Henry Kohl, who recalled, "Thereafter, I remember the term 'politically correct' being used disparagingly to refer to someone whose loyalty to the CP line overrode compassion and led to bad politics."

Hughes concludes that "political correctness" was introduced to the west via Mao Tse-Tungs's 1964 Little Red Book, and states, “...political correctness started as a policy concept denoting the orthodox party line of Chinese Communism as enunciated by Mao Tse-Tung in the 1930s."[4] Hughes emphasizes that adhering to the party line entailed both speaking and thinking "correctly" (62). He claims the term was adopted by the "American New Left in the 1960s, but with a more rhetorical than strictly programmatic sense." Hughes cites Toni Cade's 1970 work, The Black Woman, as an early example of the term's use. The text reads, "A man cannot be politically correct and a chauvinist too." Neilson refers to what he calls "The Great PC Scare" of late-1990 through early-1991, a period in which the rise in media coverage of political correctness and its association with fascism culminated in a general "hysteria."'[6]

Hughes expounds on areas of difference, including culture, ability, race, gender, wealth, and health and labels these topics as "zones of controversy," asserting that such distinctions were freely discussed in the past, but the passage of time and evolving winds of opinion have encouraged sensitivity and speech that doesn't stigmatize.[4] However, this evolution of thought is not embraced by all, and some resent what is perceived as the imposition of unwelcome, Puritanistic speech codes.

\subsection{The Case Against Political Correctness}

Criticism of political correctness often addresses censorship, oversensitivity, an erosion of originality and innovation, and bias in the education system. Lessing discusses the effects of censorship, drawing on examples of direct, state-sponsored regulation as well as the unenforceable phenomenon of political correctness. She asserts that it blunts the impulse to write or engage in discourse and creates an environment infertile to new thought, research, and criticism. She calls political correctness "a self-perpetuating machine for driving out the intelligent and the creative" and "the most powerful mental tyranny in what we call the free world."

Duignan and Gann attribute advancements in establishing ethnic, LGBTQ, and feminist studies to political correctness, claiming that the phenomenon has created an exclusive niche in education for liberals to teach in the "'programmatic' disciplines such as black studies, gay studies, women's studies, Chicano and third World studies."'[7] However, they argue that 
multiculturalism has acted to divide rather than unite, arousing hostility and a sense of "ethnic nationalism." Duignan and Gann also express regret at the decline of studies in European languages and European classics. "Instead excessive time is devoted to second-raters," referring to the works of Frantz Fanon and I Rigoberta Menchu as examples of secondrate work. They find that, in effect, political correctness has negatively impacted the education system.

\subsection{The Case for Political Correctness}

In the foreword to Feldstein's Political Correctness: A Response from the Cultural Left, Brennan questions how one defends the contradictory imposition of speech codes and explains, "For Feldstein, one doesn't defend it. It was never meant to be anything other than satire or self-criticism."[5] She summarizes his position that the current concept of political correctness was never initiated as a campaign to regulate speech, rather it comes from projection on the part of the Right, elaborating "For Feldstein, the Right projects its antidemocratic, authoritarian tendencies onto the center and the Left."

With respect to free speech, Friedman acknowledges the "occasional hypocrisy" of speech codes, stating "someone who really wants to protect that right should have challenged" the threats to free speech that political correctness imposes.[5] She elaborates, "I do not promote speech codes. I do support values of mutual respect, civility, and courtesy wherever possible." Friedman distinguishes between the concept of political correctness as a speech code and the concept of political correctness as respect. She calls to attention the fact that politically incorrect language is often employed to demean an individual or group.

Dieringer and Porretta assert that language is a result of culture and society, and societal change stimulates language change.[8] The civil rights movement brought about awareness of disability rights, culminating in new legislation that afforded persons with disabilities protections against discrimination and access to education. A new wave of legislation in the 1990s captured the sentiment of the time, employing the person-first descriptive ideology, as in the Americans with Disabilities Act of 1990 and Individuals with Disabilities Education Act in 1990. Person-first language maintains that a person has a disability but is not exclusively defined by it. Professional organizations followed suite and struck "mental retardation" from their names in favor of the more positively connoted "intellectual disability," while the Associated Press removed "mental retardation" from the stylebook in 2008. Dieringer and Porretta argue that it is important for educators to reinforce sensitive language to facilitate healthy self-images in children with disabilities. The authors' study introduces the rationale behind person-first language and addresses the impact of language choice on those with disabilities. The study also defines a relationship between cultural change and language change, linking the effects of common parlance with legislation.
Friedson compares the Merriam-Webster online definition of political correctness with the views of author Sally Satel. The author argues the formal Merriam-Webster definition neglects to address the vitriol with which the term is used by opponents.[9] He also alleges obfuscation on the part of Satel, citing a discrepancy between his understanding of the term and her position on health policy and clinical medicine, claiming that her arguments are only vaguely associated with political correctness. Underscoring the ambiguous nature of PC and the often-contentious disparity between interpretations, Friedson offers up a pithy 18 th Century quote by Bishop William Warburton clarifying the difference between orthodoxy and heterodoxy. The distinction is that one's own beliefs constitute orthodoxy, while the beliefs of others are relegated to the realm of heterodoxy.

Banning analyzes the discursive effects of the invocation of political correctness in her upper-level undergraduate classes at Kent State University. The students discussed in this study, predominantly white and middle-class, engage in discourse that the author perceives as dismissive of economic and social inequity.[10] When contemporary issues are presented in class, students reflexively discount their validity, citing the pettiness of the PC agenda. Many students attribute the Cleveland Indians baseball team's name controversy to oversensitivity, while one student opposes Title IX policy, which he understands to be a PC-motivated attempt to "make everything equal." Banning postulates that their discourse is restricted to the "fragmentary" knowledge at their disposal and indicates that their racial identity inclines them towards positions contrary to their own interests as working-class students. Indeed, one student's claim that proponents of political correctness "will sit back and expect things to be given to them because of what color they are, not what kind of person they strive to be" indicates the vast latitude in ranging interpretations of what political correctness entails.

\subsection{The Efficacy of Gender-Fair Language}

Formanowicz, Cislak, Horvath, and Sczesny undertake a crosssectional study comparing the effects of gender-fair language, or that which treats women and men equally, in Austria and Poland. The authors suggest that the term "feminism" is negatively connoted, and even women demonstrate a reluctance to associate themselves with it.[11] Feminism has historically been associated with angry women and interpreted as a threat to the institution of family, largely perpetuated by the conservative Christian movement of the 1980s and figures such as Rush Limbaugh, who coined the term, "feminazi" in 1990.

Two studies were conducted in Poland, where genderfair language is still undergoing implementation, and one in Austria, where policies are well established. Feminine job titles were embedded in a survey regarding local initiatives to promote gender equality taken by the test group, while masculine gender-neutral titles populated the survey taken by the remainder of the study's participants. The study demonstrates that Polish men's evaluation of gender-related issues is 
negatively influenced by the use of gender-fair language. The results are consistent with previous findings, which indicate that men show less enthusiasm for gender-fair language than women, although it is prudent to note that significantly more women participated in the study than men. The second study, similarly designed, revealed both women and men to respond negatively to the feminine titles.

A third study, conducted in Austria, served to shed light on whether the passage of time fosters a more favorable reception of gender-fair language. In a departure from the Polish study, the Austrian study showed men and women both perceive the feminine form more positively than the masculine form. Moreover, favorable perceptions of gender-related issues were linked to use of the feminine form.[11] These findings are significant because they provide an example of a country accepting and even embracing gender-fair terms many years after the linguistic concept was introduced. It would be helpful to have data on Austrian citizens' perceptions of the language at a nascent stage of usage to see if their position changed over time.

\section{Theories on the Pejoration of Words}

O'Neill raises questions regarding the pejoration of words in his critique of PC language. His research explores whether terms are inherently offensive or only become so after society misuses them. The author maintains that the intention behind a word's use as well as its delivery can make a term offensive, as with a schoolyard bully calling a classmate "retard." $\mathrm{He}$ describes what he calls the "euphemism treadmill,"[12] a cyclical pattern of a word's use, abuse, and the subsequent coinage of a politically correct replacement. In following this logic, the politically correct replacement term will ultimately inherit the negative connotations of its predecessor. As such, descriptors such as "physically challenged" will eventually be hurled as insults, just like "retard." Given the susceptibility of euphemisms to abuse, just as original terms are disposed to abuse, O'Neill contends that maintaining politically correct language is a futile endeavor.

As mentioned above, O'Neill's summation of the euphemism treadmill addresses health-related terms that were originally descriptive and absent value judgment, but it fails to account for words specifically created to convey a pejorative denotation and connotation, as with racial and cultural slurs. Additionally, bias can be detected in the author's references to "asinine" terms and "enforcers." [12] Labeling proponents of political correctness as enforcers suggests a perception of authority and regulation over language choice, which sheds light on potential rationale behind the aversion to political correctness.

Hughes discusses historical areas of difference with respect to race, ethnicity, and colonialism. He characterizes ancient Greeks as ethnic chauvinists and notes that the word "ethnic" is derived from the Greek word for "nation." [4] Hughes introduces the notion of "the other," a phenomenon that is exacerbated by colonialism. He presents various accounts re- lating to colonialism, including a description of the Sandwich Island inhabitants by Captain Cook in 1774 and of Ah-ChinLe's perceptions of "Western Barbarians" in 1876. The native inhabitants are invariably described as barbaric and inferior with an emphasis on differences in appearance. Hughes alleges that the notion of the other is a fundamental aspect of an individual or group's identity, and language reflects as such.

\subsection{Political Correctness and the Internet}

The advent of the internet and online discussion forums introduced a new platform for discourse and self-expression. Banks discusses the contradictions of the internet. It was originally seen as a barrier-breaking equalizer due to the close proximity people across the globe are put in, a platform for freedom of expression.[13] Yet access and anonymity pave the way for promotion of hate. Banks claims that "Technological innovation has enabled extremists and hatemongers to propagate their rhetoric and strategies, recruit, organize and unify through websites, private message boards, listservs and email."

Mantilla echoes Banks' sentiment in her discussion of misogyny and new media. She defines "gendertrolling," a subcategory of online trolling, and distinguishes it from general online harassment. While all trolling involves inflammatory comments made specifically to get a rise out of an individual or group, gendertrolling is particularly misogynistic.[14] It involves coordinated attacks by more than one person; hateful, gender-based insults such as "cunt" and "whore"; violent fantasies; treats of rape, death, and doxing; "intensity in scope and longevity"; and retaliation for speaking out.

\section{Study Design}

The current sociopolitical climate warrants a new look at an old issue. Given the prevalence of social media and other platforms for online discourse, many of Americans' conversations today is online, and memes, or captioned images that are passed between individuals, act as social currency in these online interactions. We conducted a content analysis to analyze modern language usage in the context of popular memes and provide insight on the role of political correctness in casual discourse.

Meme samples were obtained through a Google image search under the top four sub-headings: "liberal," "feminist," "racist," and "redneck." It is worth noting that "conservative" does not appear as a subheading, indicating a lack of material related to conservatism. Relatively verbose memes and memes complex in nature were not included in the sampling due to the nature of the analysis; memes were selected for simple, descriptive language.

Image macros account for $70 \%$ of the "feminist" memes and $58 \%$ of the "liberal" memes. An image macro is an image with a witty upper and lower caption in bold, white Impact font outlined in black. Out of the feminist image macros, $82.86 \%$ obeyed the image macro conventions, while $17.14 \%$ deviated, using a different typeface, color of text, or juxtaposing two 

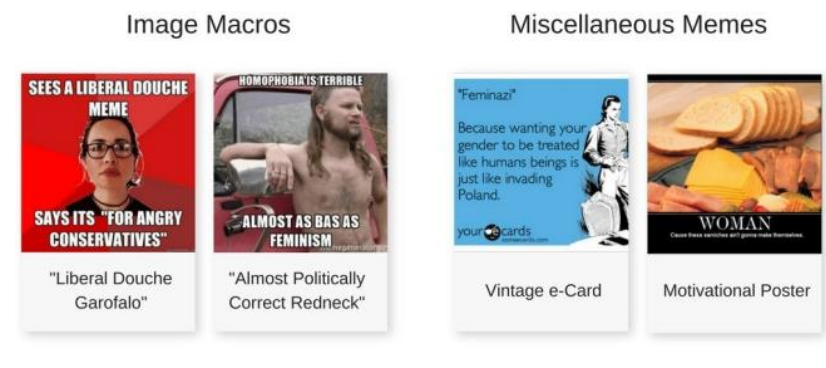

Figure 1. Sample of PC Memes

image macros side-by-side to contrast between conflicting ideals or generations. Of the liberal image macros, 27.59\% strayed from convention. Vintage card and motivational poster formats account for some of the remaining memes.

A review of existing literature reveals broad interpretations of political correctness with positions ranging from vehemently pro- to staunchly anti-PC. Given impassioned positions of both ends of the spectrum and a general rise in partisan tensions, we expect to find occurrences of PC rhetoric rising in frequency and fervency. Considering the nature of memes, which couple words and images to stress a particular point, we also expect to see a trend of painting with a broad brush. Image macros are powerful communication tools due to their ability to distill an idea into a single, sharable image.

We anticipate a rise in uninhibited language since memes are often shared among those who espouse similar beliefs. Without the fear of judgment or criticism, we expect the language and rhetoric will be more candid, likely straying outside the parameters of socially acceptable discourse. Anonymity is also likely to affect candor. Often, online interactions occur between people who will never meet. We predict the language will be more brazen since there is no fear of face-to-face social sanctions.

\section{Results}

Memes serve as a form of social currency to be traded among one's network, presumably in hopes of going viral. As such, greater value is assigned to the more popular, or "dank," memes, introducing an element of commodification. Often, the more outrageous the meme, the more exposure it gains. Therefore, sharing outrageous memes online to gain notoriety, or trolling, is increasingly commonplace and rewarded with up hundreds of thousands of "likes", strengthening an individual's social standing.

Trolling speaks to the inflammatory nature of many memes. Individuals try to antagonize and elicit a reaction, if only one of shock, from others, relying on words and images to double down on their position. These image macros underscore a resistance to language change when the intent is to accommodate the comfort level of others. One meme shows a confederate flag waving with text reading, "Liberals and politically correct republicans/Can kiss my ass!!!", while another shows an elementary computer-generated graphic of a vagina and reads, "What I do with my vagina is none of your business."

With all sub-categories analyzed, samples are both "defensive" in nature (created by members of a subcategory in defense of their views) and "offensive" in nature (created by opponents of a subcategory to delegitimize their views). There is an element of persuasion as the memes seem to reinforce certain ideals, which we see with "ethos invocations," instances in which images use respected, beloved figures to buttress their position. Within the "liberal" subcategory, Tea Party members invoked Abraham Lincoln in an "offensive" campaign, while liberals invoked Jesus in a "defensive" campaign. Within the "feminism" subcategory, Rosie the Riveter is invoked in a "defensive" campaign.

Table 1. Frequency of PC Related Terms in the Memes $(n=146)$

\begin{tabular}{lc}
\hline Common PC Terms & Frequency \\
\hline Feminazi & $2 \%$ \\
Bias & $4 \%$ \\
Fascist & $4 \%$ \\
Hate & $6 \%$ \\
Ban/Banned & $6 \%$ \\
Gender & $8 \%$ \\
Equal/Equality & $12 \%$ \\
Rights & $14 \%$ \\
Feminist/Feminism & $28 \%$ \\
\hline
\end{tabular}

Groups are often represented symbolically by an archetype, an individual who seemingly embodies the perception of the group. Celebrities figure prominently as the archetype, as with the appearance of Ashley Judd, Hillary Clinton, and The Most Interesting Man in the World in "feminist" memes. More often, the images analyzed feature generally unknown individuals whose appearance conforms to the desired stereotype, as with the "College Liberal" image, which portrays a Caucasian woman in glasses, dreadlocks, and a colorful hat. However, archetypes lack dimension. Reducing the population to archetypes has the effect of downplaying the individual while stigmatizing a particular group. Individuals are typecast without regard to their individuality, therefore perpetuating fallacies such as "southerners engage in incest," as suggested by the "Almost Politically Correct Redneck" meme. Group identity does not negate the individual. What is given is essentially a simulacrum - a copy of that which doesn't exist. We find that preconceived notions are greatly reinforced by the convergence of words and images, resulting in the dissemination of an abundance of false stereotypes. 


\subsection{Liberal Memes}

Prominent among the "liberal" memes are numerous references to the education system. Professors are characterized as biased and fascists. A black and white vintage card depicts a man with a chalkboard pointer behind a dais emblazoned with "Fascism 101" and beside a blackboard that reads, "My professor is a liberal fascist." Another meme uses the "College Liberal" image to suggest liberal indoctrination at the hands of liberal instruction. It reads, "Is 100\% open-minded and believes is peace, love and understanding/Despises you for not having the exact same liberal, hippie, progressive, socialist, atheistic beliefs and ideas that her Berkeley professor told her to have."

"Liberal" memes also allude to "playing the race card." A motivational poster-themed meme entitled "Historical Revisionists" depicts an image of Abraham Lincoln and reads, "Abe supported the Constitution like Tea Party members do. How soon before the liberals start calling Abe a racist too?" Another meme reads, "Liberals be like:/'All I gotta do is say 'racist' and I win." The meme is accompanied by heavy use of imagery, depicting a drawing of a man wearing a Bernie Sanders Button at a computer with an MSNBC sticker. Behind him on the wall are Hillary 2016 and Bernie 2016 posters, a red flag with the hammer and sickle, and a whiteboard counting down the "Internet arguments won" with 38 hatches.

In a general analysis of the "liberal" memes, liberals are depicted as:

- Crazy

- Angry

- Whiney

- Delusional

- Argumentative

- Hypocrites (intolerant)

- Tyrants/fascists

- Zealots/moral police

- Lazy/prefer freebies to hard work

- Hippies

\subsection{Feminist Memes}

Notable within the "feminist" subcategory is the appearance of "mansplaining" in one of the memes which features a woman with glasses and "NERD" written on her hand, reading "Has a PhD in the subject/You're too busy mansplaining to notice." Another meme attempts to divide the feminist community by initiating conflict with the transgender community, insinuating that Caitlyn Jenner "stole" the Woman of the Year award. A close-up of Caitlyn is featured, and the text reads, "Glamour Magazine just awarded 'Woman of the Year' to a man named Bruce/There's your war on women."
Similar to our findings among "liberal" memes, assertions of "playing the woman card" arise in the "feminism" memes. One image shows a man in the top half of the picture and a woman in the bottom half. It reads, "I have a penis, blame me for everything/I have tits, give me free stuff." A second occurrence is illustrated with a picture of a pensive woman and states, "I want equality, but I also want better treatment." A high frequency of eyeglass imagery appears, with $20 \%$ of the "feminism" memes depicting women in glasses. One meme adopting the form of a motivational poster portrays a woman with unshaven armpits and highlights a quote from Phyllis Shlafly which reads, "Feminism is doomed to failure because it is based on an attempt to repeal and restructure human nature."

Multiple samples from the "feminism" subcategory originate from the "Who needs feminism?" memes, which feature various individuals holding a whiteboard on which they have detailed why they need feminism. Initially created in support of feminism, detractors countered with their own ironic "Who needs feminism?" campaign. For example, an earnest "Who needs feminism?" meme shows a man (wearing glasses) holding a whiteboard that reads, "I need feminism because I hold gender biases - and I don't want to." In contrast, an ironic meme features a woman (wearing glasses) holding a whiteboard that reads, "I need feminism because. . . if we called it man-hate, men wouldn't help us." The image is further captioned in bold Impact typeface, "An honest feminist/How refreshing." An asterisked disclaimer appears at the bottom of the image stating, "no, she didn't really write that, there's no such thing as an honest feminist." Dishonesty and hypocrisy are coupled to discredit the ideals behind feminism in this particular meme.

Perhaps most striking in its portrayal of feminism is a meme featuring a quote by conservative Christian Pat Robertson of The 700 Club. An image of Robertson appears in the lower right corner and the text reads, "Feminism encourages women to leave their husbands, kill their children, practice witchcraft, destroy capitalism and become lesbians." Bold typeface is employed to call attention to the verbs "leave," "kill," "practice," "destroy," "become," along with the heading "Feminism." A quick glance at the image associates feminism with neglect, murder, and destruction.

Overall, our analysis of "feminist" samples indicate that feminists and females in general are portrayed as:

- Witchcraft dabblers

- Child murderers

- Homewreckers

- Biologically inferior

- Hysterical

- Whores

- Man-haters 


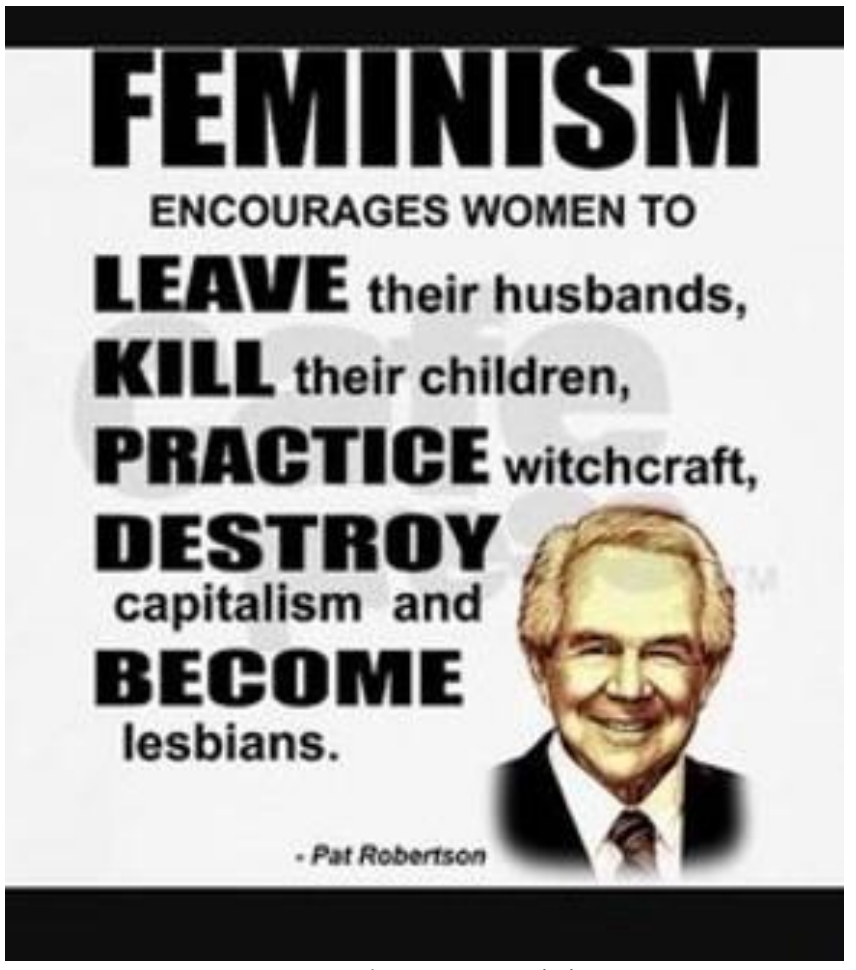

Figure 2. Pat Robertson Feminism Meme

- Prone to crying rape

- Emasculating men

- Dishonest

- In perpetual need of male assistance

- Nonsensical

\section{Directions for Future Research}

Areas of interest for further study include the impact of the alt-right movement and the influence of social media on political discourse. The administration's appointment of Breitbart News executive Stephen Bannon as Chief Strategist brought the alt-right founder into sharp focus for the next four years. Breitbart News is closely associated with the alt-right's beginnings, with their controversial headlines making headlines themselves in mainstream news outlets with allegations of racism and misogyny.

The influence of social media on political discourse is likely to grow in the coming years. The President of the United States is an avid social media user who regularly uses Twitter to communicate with the public instead of using traditional official media channels. United States history has never encountered this tendency towards public, direct communication between a President and his fellow Americans. Additionally, a recent report of the President-elect allegedly blocking an American citizen from his Twitter account has surfaced ahead of his inauguration. If true and if carried on throughout his term, this incident raises questions concerning the role of social media in political discourse and equality of access to official government communication.

\section{Author Biography}

Ashley Balcazar graduated in 2018 and is currently a graduate student at University of North Texas.

\section{References}

${ }^{[1]}$ Lindsey Bever. Students were told to select gender pronouns. one chose "his majesty" to protest "absurdity." The Washington Post, 7, 2016.

${ }^{[2]}$ David Galef. Plain talk, or case of the vanishing vocabulary. Vocabularia, 6:1-6, 2014.

${ }^{[3]}$ George Orwell. Politics and the English language. 2003.

[4] Geoffrey Hughes. Political correctness: a history of semantics and culture, volume 24. John Wiley \& Sons, 2011.

${ }^{[5]}$ Richard Feldstein. Political correctness: a response from the Cultural Left. U of Minnesota Press, 1997.

[6] Jim Neilson. The great PC scare: Tyrannies of the left, rhetoric of the right. 1995.

${ }^{[7]}$ Peter Duignan. Political correctness: A critique. 1995.

${ }^{[8]}$ Shannon Titus Dieringer and DL Porretta. Using effective language regarding disability: the role of physical educators and coaches. Physical Educator, 70(2):187, 2013.

${ }^{[9]}$ Eliot Freidson. Whose PC is correct? Society, 39(4):1720, 2002. DOI:10.1007/BF02712633

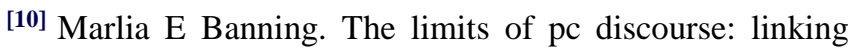
language use to social practice. Pedagogy, 4(2):191-214, 2004.

[11] Magdalena M Formanowicz, Aleksandra Cisłak, Lisa K Horvath, and Sabine Sczesny. Capturing socially motivated linguistic change: how the use of gender-fair language affects support for social initiatives in Austria and Poland. Frontiers in psychology, 6:1617, 2015.

https://doi.org/10.3389/fpsyg.2015.01617

${ }^{[12]}$ Ben O'Neill. A critique of politically correct language. The independent review, 16(2):279-291, 2011.

[13] James Banks. Regulating hate speech online. International Review of Law, Computers \& Technology, 24(3):233-239, 2010.

https://doi.org/10.1080/13600869.2010.522323

${ }^{[14]}$ Karla Mantilla. Gendertrolling: Misogyny adapts to new media. Feminist Studies, 39(2):563-570, 2013. 